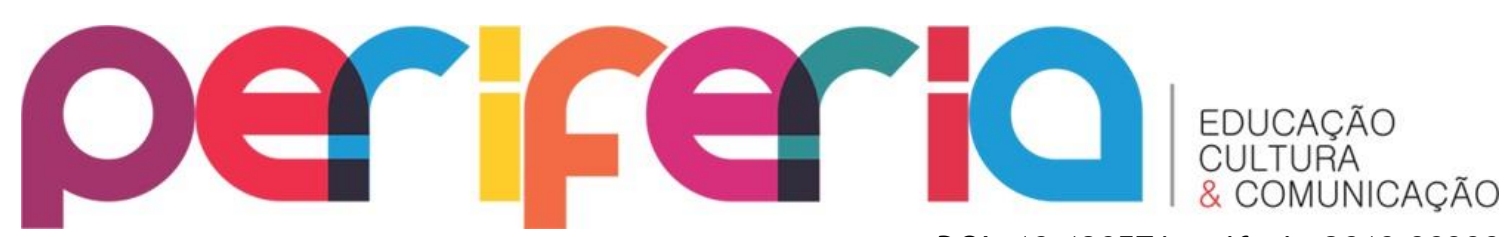

DOI: $10.12957 /$ periferia.2019.39390

\title{
MEMES NO APRENDIZADO DE LÍNGUAS: UMA PRÁTICA MULTILETRADA NA FORMAÇÃO DOCENTE PARA A JUSTIÇA SOCIAL
}

\author{
Janaina da Silva Cardoso ${ }^{1}$ \\ Universidade do Estado do Rio de Janeiro - UERJ \\ Alessandra Cristina Bittencourt Alcântara ${ }^{2}$ \\ Centro Federal de Educação Tecnológica Celso Suckow da Fonseca (CEFET/RJ) \\ Ana Beatriz Simões da Matta ${ }^{3}$ \\ Instituto Federal Fluminense - IFFluminense
}

\section{Resumo}

A opção argumentativa deste artigo surge das discussões sobre práticas pedagógicas de professores de línguas adicionais do grupo de pesquisa EAL Ensino e Aprendizagem de Línguas: abordagens, metodologias e tecnologias (CNPq/UERJ) e reiteradas em leituras e estudos da disciplina de pós-graduação Processos de compreensão na era digital: a oralidade e a escrita. 0 foco da discussão é a crença de que a formação docente na contemporaneidade não deva ser vista como prescrição, mas como reflexão e atendimento das singularidades dos contextos educacionais de forma crítica. Sendo assim, o texto materializa o ensejo por discutir, atualizar e aproximar o conceito de multiletramentos à formação de professores. Para tanto, o texto é apresentado em quatro partes: considerações iniciais, que apresenta brevemente o conceito de multiletramentos; uma discussão sobre a formação docente, que busca a justiça social; um exemplo de aplicação de memes para o processo de ensinoaprendizagem de espanhol e finalmente, o texto é concluído com algumas considerações finais.

Palavras-chave: aprendizado de línguas; multiletramentos; memes

\footnotetext{
1 Professora Adjunta do Setor de Língua Inglesa, atuando nos cursos de graduação e pósgraduação em Língua Inglesa e no mestrado e doutorado na área de Linguística. janascardoso1@gmail.com

2 Doutoranda em Linguística pela Universidade do Estado do Rio de Janeiro, Professora EBTT do CEFET/RJ, Campus Maracanã. alessandrabittencourt@gmail.com

${ }^{3}$ Especialista em Ensino de Línguas Estrangeiras- CEFET-RJ; Mestranda em Linguística na UERJ; Professora do Ensino Básico, Técnico e Tecnológico do Instituto Federal Fluminense. anabeatrizsimoes@hotmail.com
} 


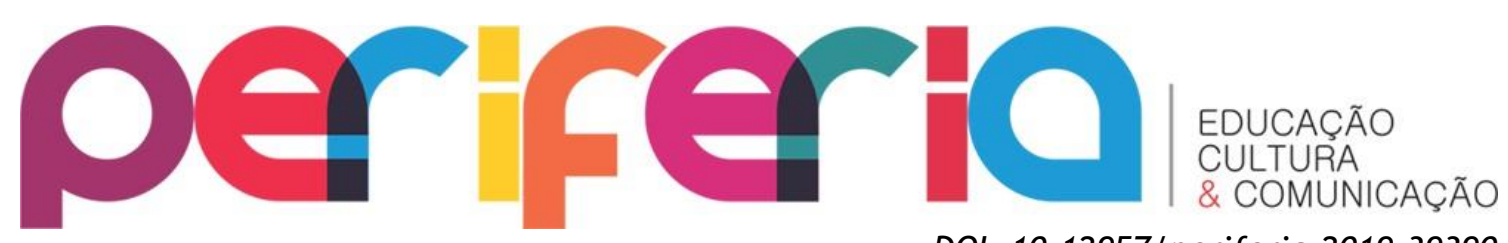

DOI: $10.12957 /$ periferia.2019.39390

MEMES IN LANGUAGE LEARNING:

A MULTILITERATE PRACTICE IN THE TEACHER EDUCATION FOR SOCIAL JUSTICE

\begin{abstract}
The argumentative thesis of this article arises from the discussions on pedagogical practice of language teachers in the research group EAL - Ensino e Aprendizagem de Línguas: abordagens, metodologias e tecnologias (CNPq, /UERJ) and was reiterated in readings and studies of a postgraduate course discipline. The focus of this discussion is the belief that teacher education in contemporary times has not to be seen as a prescription, but as reflection and attention to the singularities of educational contexts in a critical way. Thus, the text materializes the opportunity to discuss, update and bring the concept of multiliteracies closer to teacher development. To do so, the text is presented in four parts: initial considerations, which briefly presents the concept of multiliteracies; a discussion on teacher education, which seeks social justice; an example of application of memes to teaching and learning of Spanish and finally, the text is closed with some final considerations.
\end{abstract}

Keywords: language learning; multiliteracy; memes 


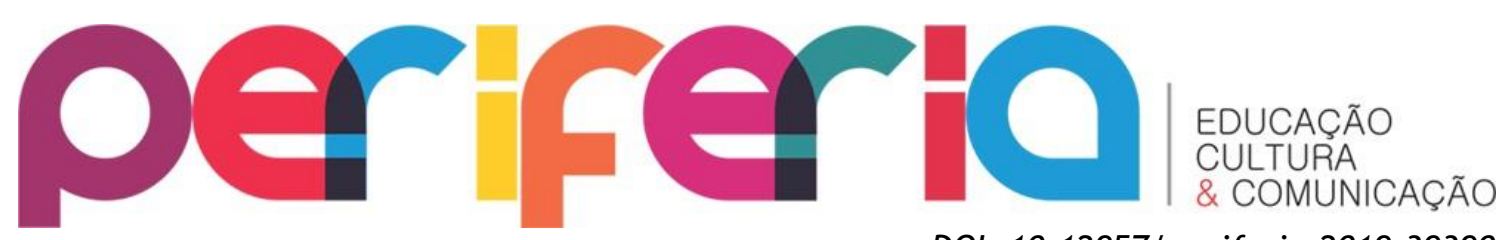

DOI: $10.12957 /$ periferia.2019.39390

MEMES EN EL APRENDIZAJE DE LENGUAS:

UNA PRÁCTICA MULTILITERADA EN LA FORMACIÓN DOCENTE A LA JUSTICIA SOCIAL

\section{Resumen}

La opción argumentativa de este artículo surge en las discusiones sobre prácticas pedagógicas de profesores de lenguas adicionales del grupo de investigación EAL - Ensino e Aprendizagem de Línguas: abordagens, metodologias e tecnologias (CNPq/UERJ) y reiteradas en lecturas y estudios de una asignatura del curso de posgrado Processos de compreensão na era digital: a oralidade e a escrita. El enfoque de la discusión es la creencia de que la formación docente en la contemporaneidad no debe ser vista como prescripción, sino como reflexión y atención a las singularidades de los contextos educativos de forma crítica. Así siendo, el texto materializa la ocasión por discutir, actualizar y aproximar el concepto de multiliteracidad a la formación de profesores. Para ello, el texto se presenta en cuatro partes: consideraciones iniciales, que presenta brevemente el concepto de multiliteracidad; una discusión sobre la formación docente, que busca la justicia social; un ejemplo de aplicación de memes para el proceso de enseñanza-aprendizaje de español $y$, finalmente, el texto se concluye con algunas consideraciones finales.

Palabras clave: aprendizaje de lenguas; multiliteracidad; memes 


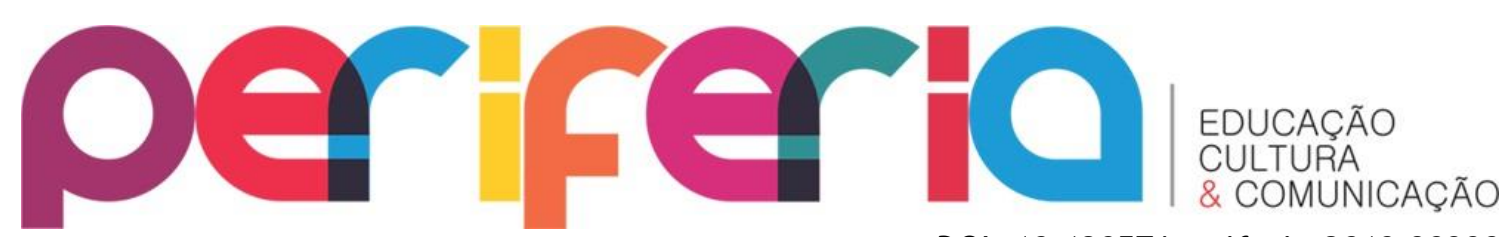

\section{CONSIDERAÇÕES INICIAIS}

DOI: $10.12957 /$ periferia.2019.39390

Pensar a formação de professores de línguas adicionais ${ }^{4}$ na contemporaneidade e no contexto brasileiro requer um esforço por não se inclinar a prescrever práticas e currículos, principalmente diante de um país com dimensões continentais como o Brasil. A multiplicidade de concepções formativas é, de fato, uma característica das instituições legalmente autorizadas (ou que se autorizam) a formar este profissional educativo. Mas é preciso credenciar discursos, refletir, e principalmente, lutar por melhorias e implementação de políticas de valorização do espaço educacional, do docente e da docência, visto que, como nos ensina Freire (2000, [1968]), educar é ato politicamente engajado.

Este trabalho materializa o ensejo por discutir, atualizar e aproximar conceitos, como o de multiletramentos à formação de professores, desejo este suscitado por nossas experiências de docência, que, consequentemente, geraram (e geram) saberes. Tardif (2002), ao categorizar os saberes implicados na atividade docente ${ }^{5}$, qualifica os oriundos do exercício profissional docente como experienciais, produzidos pelos professores na vivência cotidiana escolar e no diálogo com discentes e outros docentes. Os saberes experienciais, "incorporam-se à experiência individual e coletiva sob a forma de habitus e de habilidades, de saber-fazer e de saber ser" (TARDIF, 2002 p.38).

Cumpre destacar que este anseio não se adjudica ao discurso da "falta" na formação de professores, pois a pesquisa não tem a pretensão de apontar "faltas" e sim partir para uma discussão tomando como base uma atividade desenvolvida por alunos da rede técnica federal. Deste modo, trata-se de uma

4 Alinhamo-nos à terminologia línguas adicionais por comungar, à luz de Schlatter e Garcez (2012), da premissa de que idiomas são adicionados ao repertório linguístico do discente e não devem ser considerados elementos estrangeiros, estranhos e exteriores ao que aprende e, também, ao que ensina. Cardoso (2017) também defende o uso do termo língua adicional, para evitar o apagamento de línguas não europeias e a lógica binária (língua nativa vs língua do outro). Ao defender esta ideia, e de afirmar que no caso do Brasil, trata-se de uma política linguística, cita Rajagopalan (2003) e Graddol (2006).

5 Tardif (2002, p.27) propõe que o saber docente é "saber plural, formado de diversos saberes provenientes das instituições de formação, da formação profissional, dos currículos e da prática cotidiana" 


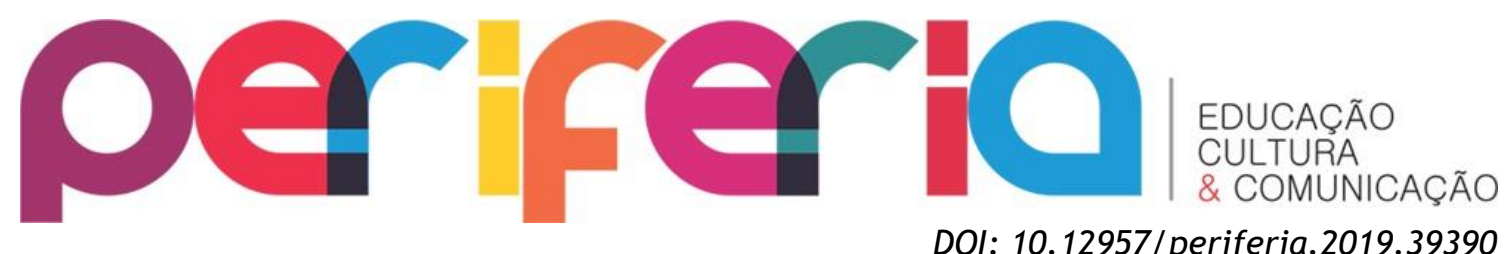

pesquisa-ação (DINIZ-PEREIRA; ZEICHNER 2011; PIMENTA, FRANCO 2014; THIOLLENT 2006a, 2006b, 2011), em que a reflexão do professor parte de sua própria prática e essa prática irá influenciar em ações futuras, o processo açãoreflexão-ação mencionado por Bortoni-Ricardo (2008, p. 48).

Este trabalho tem como objetivo principal contribuir com as pesquisas nas áreas de linguística aplicada, multiletramentos e educação, em especial no que tange a currículos e a formação de professores. Primeiramente, discute-se a formação de professores para justiça social, uma reflexão a partir de uma análise sociopolítica, fomentando o desenvolvimento profissional alinhado aos multiletramentos. Em seguida, inicia-se uma discussão sobre os termos letramento(s), alfabetismo, múltiplos letramentos e multiletramentos de modo a esclarecer o objetivo da pesquisa com multiletramentos. Posteriormente, apresentam-se relatos de atividades calcadas na pedagogia de multiletramentos em aulas de espanhol no ensino médio técnico da rede pública federal. Por fim, o artigo é concluído com as considerações finais, que revisitam os objetivos traçados para o trabalho e seus resultados.

\section{FORMAÇÃO DE PROFESSORES PARA A JUSTIÇA SOCIAL}

Diversos autores (CELANI 2010; LEFFA, 2008, LIBERALI 2015; MATEUS, OLIVEIRA 2014; NÓVOA, 1992; ROCHA, BRAGA, CALDAS, 2015; ROCHA, MACIEL 2013; SCHON, 1992 dentre outros) apontam a reflexão na formação de professores como fator essencial no processo de constituição deste profissional da educação. Contudo, Rodgers (2002, p.843) assinala que comumente o ato de refletir torna-se tão intrínseco à docência que se institui como "jargão técnico" da área, "tornando-se tudo para todos". Em outras palavras, parece haver uma banalização do ato de refletir no campo da docência.

É inquestionável a importância, não só do processo reflexivo, como também da percepção da realidade na qual a prática docente se institui. Na esteira da interpretação de Jorge (2016), a reflexão é, certamente, uma evolução à formação docente fundamentada no tecnicismo; no entanto, "o modelo da reflexão por si só não parece atender às demandas que se 


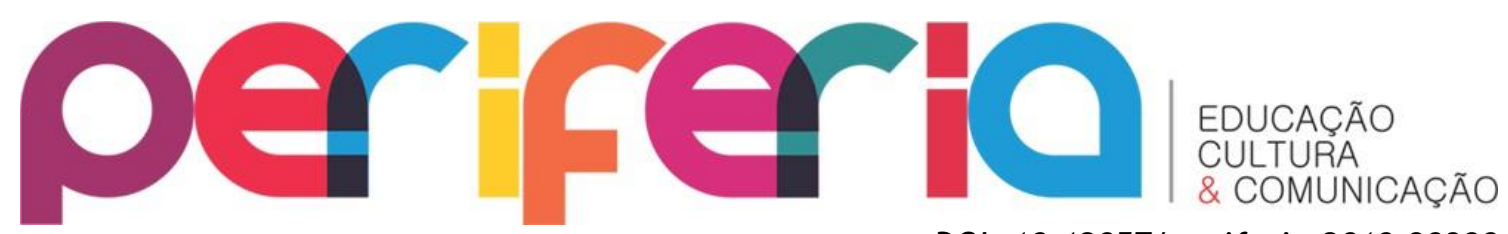

DOI: $10.12957 /$ periferia.2019.39390 apresentam para a atuação do professor na escola" (JORGE, 2016, p. 133). Estas demandas compreendem a multiplicidade identitária dos que se relacionam com o processo educativo, seja de raça, gênero, condição social, etc. Jorge (2016) autoriza o pensamento de Zeichner (2008) ao propor uma alternativa à formação de professores.

A formação docente reflexiva, que realmente fomenta o desenvolvimento profissional, deveria ser somente apoiada, em minha opinião, se ela estiver conectada a lutas mais amplas para a justiça social e contribuir para a diminuição das lacunas na qualidade da educação disponível para estudantes de diferentes perfis, em todos os países do mundo. (ZEICHNER, 2008, p. 244 apud JORGE, 2016, p. 133)

Assim sendo, Jorge (2016) resume sua proposta de formação docente pautada na justiça social (ainda que o termo apresente polêmicas e diversas definições). Formação esta que promova, sim, uma reflexão sobre a realidade escolar, mas que se simbiotize a uma análise sociopolítica, principalmente das estruturas que impedem o reconhecimento e o respeito a identidades híbridas. Educação é ato político e, como tal, a escola urge mover-se de um isolamento como instituição “douta” para ser o espaço propulsor da formação ética cidadã.

E nesse contexto, posicionamo-nos a respeito de uma formação docente para a justiça social alinhada aos multiletramentos. Apesar de Jorge (2016) filiar-se em seu artigo aos letramentos críticos a fim de problematizar questões sociais, optamos pela noção de multiletramentos - convém lembrar que a ideia de letramentos críticos também está alinhada a de multiletramentos, como postula Rojo (2012) - por ser uma interseção da multiplicidade cultural e semiótica dos textos que circulam na sociedade.

Diante destas constatações sobre a formação docente, parece ser preciso propor letramentos, tanto de alunos como de (futuros) professores, que ultrapasse as “fronteiras da letra”. Para isso, na próxima seção, realizamos um sucinto delineamento de como o letrar adquiriu forma pluralizada, além de elencar conceitos e aclarações sobre os multiletramentos, proposta na qual nos inscrevemos na busca por uma docência mais justa e pluralizada. 


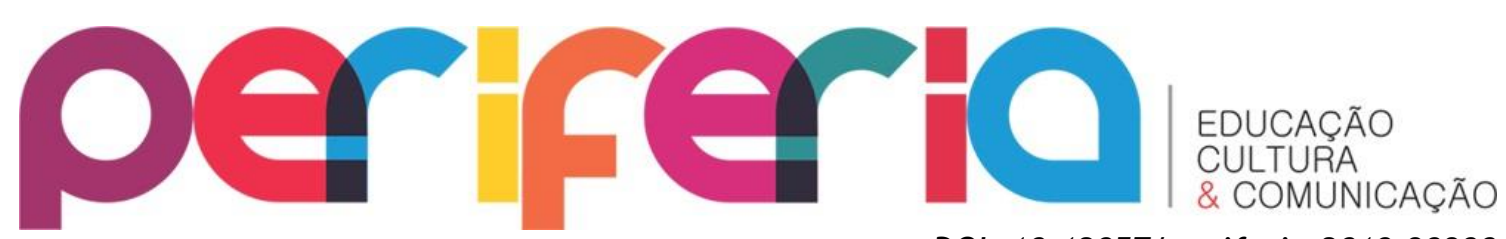

DOI: $10.12957 /$ periferia.2019.39390

DO LETRAR AO MULTILETRAR: PROFESSORES PARA ALÉM DO “LETRAMENTO DA LETRA"

A superação do entendimento do ato de ler, pautado na mera “codificação- decodificação" de fonemas e grafemas, basilar ao conceito de alfabetização, possibilitou uma gama de acepções atribuídas na literatura ao letramento. Segundo Silva (2011), o termo surge em 1970 e deriva da preocupação de educadores em alinhar-se aos postulados da educação dialógica de Paulo Freire e sua “leitura de mundo”, anterior à da palavra: ler, na ótica freireana, é ato político e não o domínio da mecânica em vocalizar letras.

Todavia, Soares (2017 [1998], p.15) aclara que Mary Kato é quem referenda, pela primeira vez na língua portuguesa, a palavra letramento. Em “No mundo da escrita: uma perspectiva psicolinguística”, Kato (1986) assume que a língua falada culta "é consequência do letramento", isto é, do contato com a escolarização e com a “norma-padrão”. Mas é Tfouni (1988), com “Adultos não alfabetizados: o avesso do avesso", que realiza o primeiro intento em diferenciar alfabetização e letramento, o que relega a entrada deste último ao estatuto de termo técnico no léxico da Educação e das Ciências Linguísticas no Brasil.

Soares (2017 [1998], p.39,40) esclarece que um indivíduo alfabetizado não é necessariamente letrado, visto que alfabetizar denota o conhecimento, como exposto anteriormente, da tecnologia instrumental em codificar e decodificar letras e sons. Por sua vez, o indivíduo letrado supera este tecnicismo, e lança mão dele (ou não) ${ }^{6}$ para inserir-se nas práticas sociais de leitura e escrita: letramento, nesta visão pressupõe a incorporação à comunicação em sociedade.

Outro termo que merece ser elucidado é o de alfabetismo, que abarca a faceta linguístico-cognitiva do ato de ler e escrever, em uma dimensão individualizada (ROJO, 2009). Capacidades de leitura e escrita, estratégias e

6 Soares (2007 [1998], p.24), ao contrapor letramento e alfabetização, afirma que um indivíduo pode não ser alfabetizado, mas por envolver-se em práticas sociais de leitura e escrita, como o reconhecimento de placas e a solicitação da escrita de cartas é, de certo modo, letrado. Igual ocorrência é citada pela autora quando a criança manuseia livros e diversos gêneros textuais, no intento inicial por integrar-se aos modos de comunicação social.

Periferia, v. 11, n. 1, p. 54-72, jan./abr. 2019 


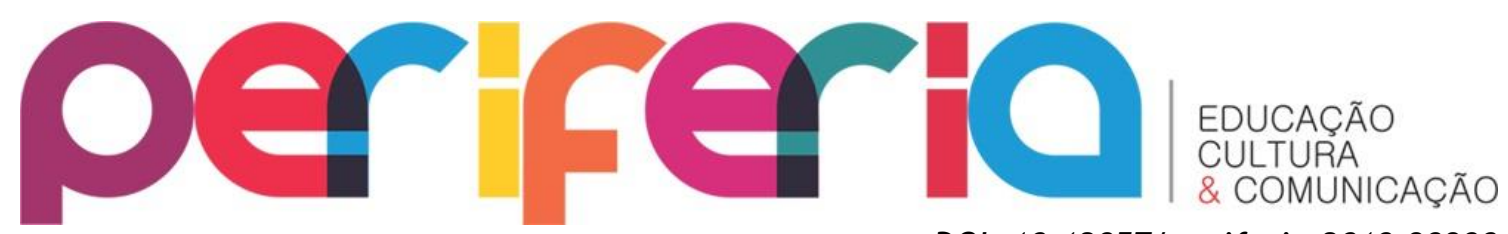

DOI: $10.12957 /$ periferia.2019.39390 competências são termos que se aproximam mais deste conceito, que, no ponto de vista de Rojo (2009), compreende as práticas escolares valorizadas e aceitas no espaço escolar. 0 alfabetismo, "conjunto de competências e habilidades ou de capacidades envolvidas nos atos de leitura e escrita dos indivíduos", pode ser medido e definido, segundo a autora, pelos exames nacionais e pelo INAF'

Diferentes correntes teóricas debruçam-se (debruçaram-se e debruçarse-ão) a definir e ampliar o que se entende como letramento, bem como sugerir propostas educacionais e estabelecer o termo de modo pluralizado, seguido de diversas denominações. Pela extensão deste trabalho, não nos lançaremos a catalogar e definir todas, mas ressaltar a nossa posição diante dos multiletramentos e sua importância na inserção da formação de professores.

Rojo (2009) atribui a obra de Street (1984) como divisora de águas na concepção da pluralização do termo, por inaugurar os novos estudos do letramento (NEL/NLS), disseminada no Brasil por Kleiman (1995). Esta escola linguística toma como fundamental a característica heterogênea das práticas sociais de leitura e escrita e uso da língua e linguagem. Rojo (2009, p. 102) destaca a faceta sociocultural nas práticas de letramento. Em Street (2003, p. 7 apud ROJO, 2009, p.102), aclara-se a posição com relação à heterogeneidade:

[...] implica o reconhecimento de múltiplos letramentos que variam no tempo e no espaço, mas que são também contestados nas relações de poder. Os [novos estudos dos letramentos] NLS não pressupõem coisa alguma como garantida em relação aos letramentos e às práticas sociais com que se associam, problematizando aquilo que se conta como letramento em qualquer espaço-tempo e interrogando sobre quais letramentos são dominantes e quais são marginalizados ou de resistência. (STREET, 2003, apud ROJO, 2009, p. 102).

Desse modo, como salienta Rojo (2009), é justificada a adição do morfema de número ao termo. Não se pode pensar apenas em um letramento, único, valorizado pelo espaço escolar, mas sim em letramentos que denotam a multiplicidade de práticas sociais. Cumpre destacar, como aporta Hamilton (2002, p.4 apud ROJO, 2009, p. 102), em seu intuito por distinguir letramentos dominantes (valorizados legal e culturalmente, com agentes ditos

7 Indicador de alfabetismo funcional.

Periferia, v. 11, n. 1, p. 54-72, jan./abr. 2019 


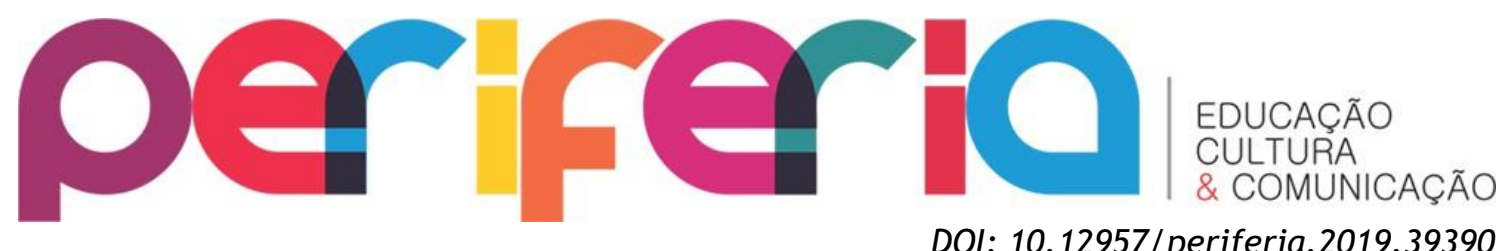

“autorizados”, como professores, advogados, juristas, dentre outros) e vernaculares (ou "autogerados", não regulados ou controlados, de origem na vida cotidiana), que não há uma polarização entre dominante e marginalizado, por serem categorias interligadas. O que ocorre é uma desvalorização dos vernaculares, desprezados recorrentemente pela cultura oficial e considerados, por Rojo (2009), como de resistência.

A exigência de um novo pensar sobre os letramentos deriva do uso das tecnologias digitais na contemporaneidade, o que acarretou em mudanças nos modos de produção e circulação de informações. Rojo (2009) elenca pontos estratégicos que suscitaram a mudança do olhar ao letramento, a saber: o distanciamento da circulação da informação em meios impressos, a reconfiguração da noção de espaço e de tempo e a multissemiose dos textos atuais, nos quais a leitura já não é mais a da palavra, mas sim a relação desta com outras modalidades da linguagem ou com múltiplas semioses.

Entretanto, como novamente adverte Rojo (2013, p. 7), as mudanças nos novos letramentos não são somente ato de consequência de avanços tecnológicos. Há, de fato, o surgimento de uma nova mentalidade, que pode ser potencializada ou não pelas tecnologias digitais. A esse respeito, Silva (2002 [1998]) sublinha que as tecnologias digitais potencializam autorias pelo ciberespaço e propiciam interatividade entre os sujeitos; porém, não são elementos determinantes. Dito de outro modo, o surgimento desta "nova mentalidade" é maximizado pelas tecnologias digitais, mas ela pode ser expressa em outros meios, como o grafite, a composição de raps, o desenho, a escrita no papel, etc.

Se a contemporaneidade impele-nos a múltiplos desafios, então por que não pensar em multiletramentos?

Em 1996, um colóquio do Grupo de Nova Londres aponta a necessidade de uma pedagogia dos multiletramentos que contemple os novos letramentos emergentes na sociedade atual, não somente por considerar práticas letradas oriundas das TICs, mas também a inclusão nos currículos da variedade cultural, presentes nas salas de aula e marcadas pela intolerância em conviver com a alteridade. 


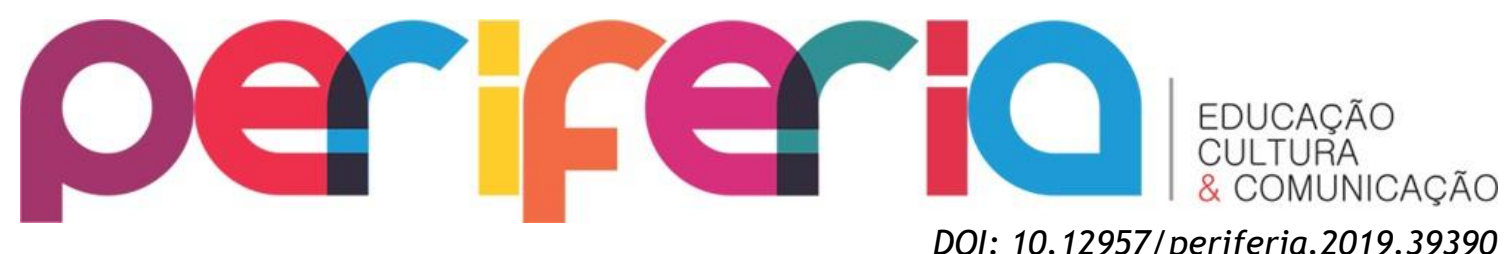

Rojo (2012) explicita que o ponto de interseção entre novos letramentos de caráter multimodal e hipermidiáticos e a multiculturalidade das sociedades globalizadas constitui o que se cunhou como multiletramentos. Cabe destacar que o termo se distancia da noção de letramentos múltiplos ${ }^{8}$, por este denotar apenas a variedade de práticas letradas existentes na sociedade contemporânea, valorizadas ou não, ao passo que os multiletramentos, como exposto anteriormente, indicam duas multiplicidades da esfera social atual: a cultural populacional e a semiótica, representada pela diversidade dos gêneros existentes na sociedade:

[...] por um lado, a multiplicidade de linguagens, semioses e mídias envolvidas na criação de significação para os textos multimodais contemporâneos e, por outro, a pluralidade e a diversidade cultural trazida pelos autores/leitores contemporâneos a essa criação de significação (ROJO, 2013, p. 14).

Na multiplicidade cultural, a hibridização é orientação de base. Rojo (2012) reconhece que desde o início do século XX, as sociedades são híbridas e fronteiriças. Há uma provocação ao propor o aposto "senão desde sempre" seguido ao estabelecimento temporal. Desse modo, na esteira de García Canclini (2008 [1989]), já não há mais sentido em polarizar/ditocomizar questões culturais, como civilização/barbárie e erudito/popular: os híbridos, as mestiçagens e as misturam reinam cada vez mais soberanas". Em sua ótica, a produção de cultura é caracterizada pela desterritorialização, descoleção e hibridação. Em outros termos, recomenda-se descolecionar monumentos patrimoniais escolares a partir da introdução de gêneros do discurso ditos "impuros" e de diferentes mídias, tecnologias, variedades, línguas e linguagens.

A autora conclama, então, uma nova percepção à ética e às estéticas nos multiletramentos, já não mais baseadas em um direito de autoria único, proprietário, mas sim compartilhado de forma reticular e pautado em ações dialógicas com novos interpretantes e calcada em um letramento crítico,

8 Em Rojo (2009), os termos são apresentados em sinonímia. Em Rojo (2012, p.13), a autora propõe a diferenciação dos conceitos. 


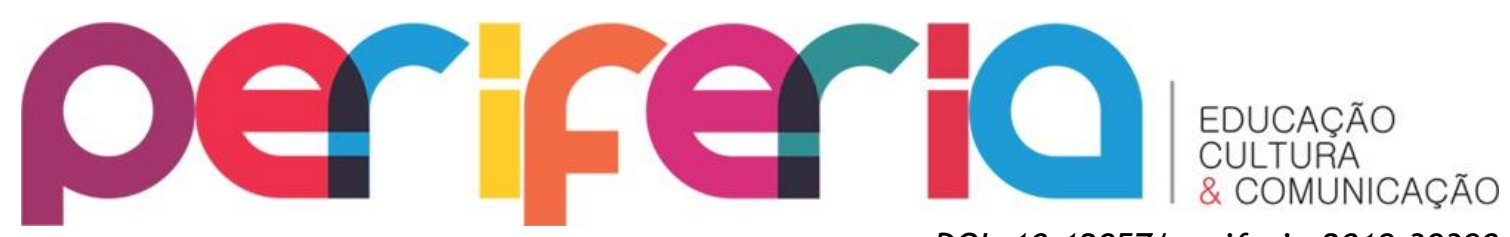

DOI: $10.12957 /$ periferia.2019.39390 problematizador. Decerto que as tecnologias digitais, artefatos que propiciam a liberação do polo da emissão (LEMOS, 2013 [2002]) na cibercultura, potencializam a autoria nas redes e colaboram com a denúncia e problematização de mazelas sociais.

Uma educação linguística, defendida em Kalantzis e Cope, 2006), resume-se a proporcionar aos discentes projetos de futuro que se alinhem à diversidade produtiva, ao pluralismo cívico e às identidades multifacetadas. Desse modo, apresentamos na próxima seção um relato de atividades que se dispõem a abordar os multiletramentos em aulas de espanhol como língua adicional no contexto do ensino médio integrado da Rede Federal.

\section{MEMES EM SALA DE AULA DE ESPANHOL COMO LÍNGUA ADICIONAL: APLICAÇÃO E EXPERIÊNCIA NARRADA}

É fato que, com o advento das tecnologias digitais, modificam-se os modos de ser e estar na contemporaneidade e, assim, a comunicação em sociedade é afetada. Com isso, novos comportamentos comunicativos surgem na esteira da ampliação das possibilidades de produção e circulação de gêneros textuais. Como nos aponta Lima e Castro (2016. p, 39), outras formas de "querer-dizer" implicam distintos processos comunicativos, e, como consequência, surgem novos gêneros.

Nesse contexto de emergência de novas práticas comunicacionais (LEMOS, 2013 [2002]) é que se cogita a possibilidade de inserir os memes no trabalho com o espanhol como língua adicional. O meme, entendido aqui como gênero textual emergente do ambiente digital, produzido e compartilhado ao sabor dos acontecimentos sociais, ganha terreno neste contexto cibercultural pela rapidez em sua disseminação.

Dentre as diversas definições de meme existentes, filiamo-nos à seguinte:

artefato cultural e textual do ambiente virtual, elementos que nas redes sociais transportam informações e carregam ideias, emoções, argumentos e pontos de vista, configurando-se de maneira diferenciada e se consolidando como gênero. (LIMA; CASTRO, 2016) 


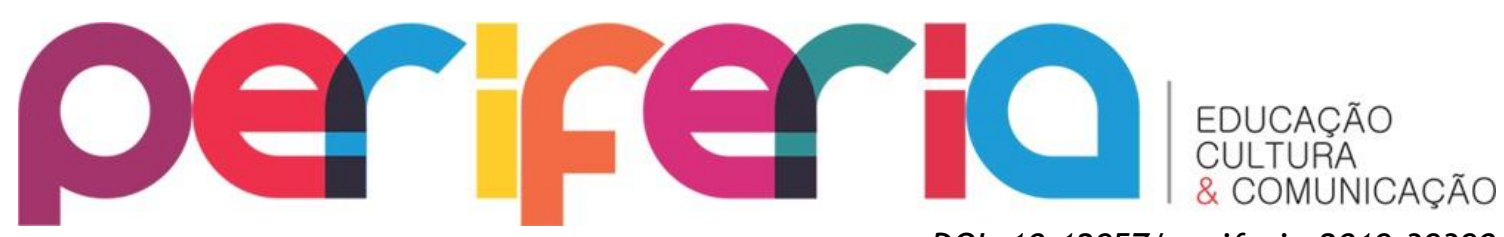

DOI: $10.12957 /$ periferia.2019.39390

A plasticidade derivada da rápida veiculação deste gênero pelas redes sociais, sublinhada por Lima e Castro (2016, p. 40), permite que usuários modifiquem, criem e recategorizem os memes em diferentes semioses. Em outros termos, memes podem ser (e, de fato, o são) textos multimodais.

A respeito da definição de multimodalidade, Kress e Van Leeuwen (2001) aportam que este conceito se relaciona a um campo de estudo que aborda formas de comunicação produzidas por recursos semióticos diversos e lança-se a entender como esses recursos operam para construir signos em contextos sociais concretos.

A ideia de que a multimodalidade é a combinação de mais de uma linguagem na comunicação segue Hemais (2015, p.32), para quem este fenômeno não é atual. A autora argumenta que a comunicação humana é essencialmente multimodal, porque diversos modos semióticos não funcionam separadamente, mas em conjunto, como gesticular e falar simultaneamente. A partir deste pensamento, a multimodalidade

é caracterizada pela presença de mais de uma modalidade de linguagem, ou seja, a copresença de vários modos de comunicação. O que é importante assinalar é que os modos interagem na construção dos significados da comunicação social, e cada modo contribui para os significados de acordo com sua capacidade de criar significados. [...] o verbal e o visual se complementam, e potencializam os efeitos de sentido para o leitor. (HEMAIS, 2015, p. 32)

Hemais (2015, p.31) aponta que nos materiais didáticos de ensino de língua inglesa são inseridos elementos com diferentes linguagens ou modos de comunicação. Tal inserção reflete a forma de comunicar na contemporaneidade, já que diversos tipos de linguagem ocorrem simultaneamente no ato de comunicar.

E é essa multimodalidade, atrelada às novas formas de comunicação social oriundas das tecnologias digitais, que motiva a inclusão por uma professora de espanhol do Instituto Federal Fluminense do meme, por entender, com Rojo (2013, p.20), que "já não basta mais a leitura do texto verbal escrito - é preciso colocá-lo em relação com um conjunto de signos de outras 


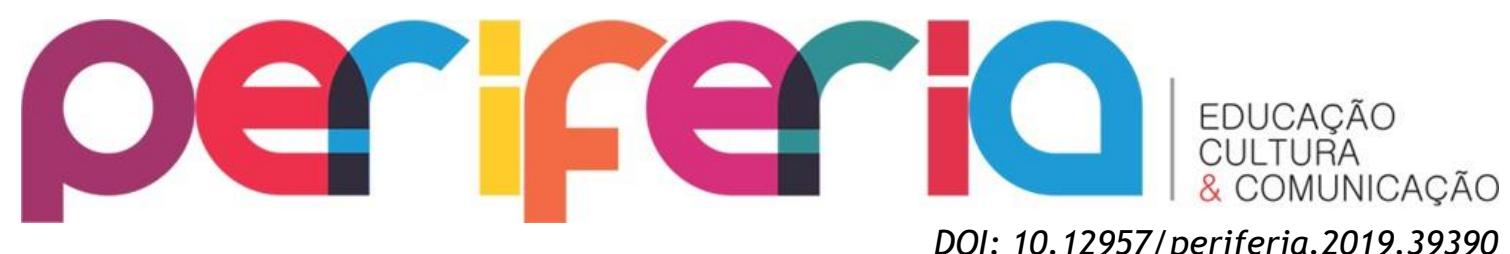

modalidades de linguagem (imagem estática, imagem em movimento, som, fala)".

A proposta foi lançada aos alunos durante o período de preparação para a Feira Anglo-Hispânica, iniciativa conjunta das professoras de língua inglesa e língua espanhola da Instituição. O evento objetiva disseminar a cultura dos países hispanos e anglófonos, em sua variedade de artefatos e possibilidades artísticas, a fim de que a comunidade escolar opere na multiplicidade de culturas e perceba-se como integrante de uma diversidade cultural.

De forma a organizar a proposta com os memes, dividiremos os movimentos didático-pedagógicos em etapas, com um breve relato, devido à extensão deste trabalho.

A etapa inicial ocorreu no laboratório de informática da instituição. Solicitou-se aos alunos que pesquisassem sobre memes e sua importância na sociedade: onde e como circulavam, quem os produz, para quem, em que circunstâncias. Espantosamente, os alunos retiravam seus celulares dos bolsos de modo para responder as perguntas lançadas. Muitos já produziam memes em seus telefones e até possuíam aplicativos capazes de "gerar memes". Deixavam a fixa tela dos desktops e acessavam os “mobiles".

Decerto, a mobilidade afeta a docência e aprender com os aplicativos e de forma ubíqua (SANTAELLA, 2013) é realidade no espaço escolar. Talvez, em um próximo trabalho com os gêneros digitais, neste contexto, já nem seja mais preciso deslocar-se ao “laboratório", pelo fato de um toque móvel substituir a imobilidade de um computador de mesa.

Na segunda etapa, a professora de espanhol solicitou que analisassem o gênero em seus aspectos verbais e não-verbais. Daí a questão multimodal tornou-se bastante evidente. Nos relatos dos alunos, ficou claro que, para a construção da ironia no meme, não se pode dissociar a escrita da imagem. Dito de outro modo, para eles, a "graça não funcionava" se apartássemos as imagens das frases escritas.

$\mathrm{Na}$ terceira etapa, os alunos, ansiosos por produzir os memes dos países com os quais se responsabilizaram, utilizaram-se muito mais de seus "geradores de memes" em aplicativos de celular do que os computadores dos laboratórios. 


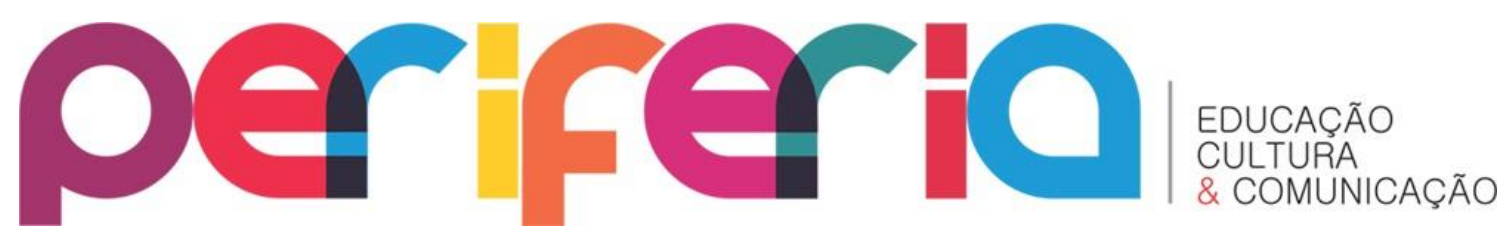

DOI: $10.12957 /$ periferia.2019.39390

Como, em aulas anteriores, já havíamos discutido acerca dos estereótipos culturais, a professora de espanhol indagou-lhes se os memes poderiam reforçar alguns deles. Os discentes afirmaram positivamente, por ser um gênero irônico, mas, em juvenil astúcia, relataram saber que as culturas não se baseavam apenas em elementos "representativos" (p.ex. o touro a Espanha, o samba o Brasil e o hambúrguer os Estados Unidos) e propuseram-se a confeccionar memes que também abarcassem essa "ironia do estereótipo".

De maneira a exemplificar o efeito de sentido irônico, passamos a apresentar a produção de um desses memes e a narrativa de produção de um de seus autores. 0 nome foi preservado para resguardar o sigilo identitário.

Figura 19: Produção de grupo 7 do curso de Automação do IFF - Campus Santo Antônio de Pádua.

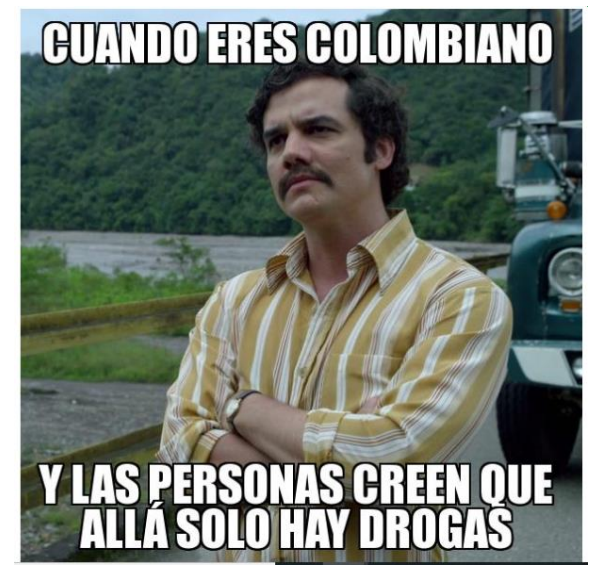

"Fizemos esse meme porque pensamos justamente na graça que ia ter de falar que na Colômbia não tem só droga, né? E o Pablo Escobar era um traficante e ele mesmo fica irritado de falar que lá só tem drogas, só que com a pesquisa que a gente fez vimos que na Colômbia não tem só drogas. Tem até as pinturas do Botero que trabalham essa coisa da gordofobia, museu do ouro. Então é isso, da gente deixar um pouco esses rótulos do país e conhecer um pouco mais do país mesmo". (Integrante do Grupo 7 - do curso de Automação do IFF - Campus Santo Antônio de Pádua)

É perceptível, na narrativa do integrante do grupo 7, a escolha da imagem do ator

9 "Quando você é colombiano e as pessoas acham que lá apenas há drogas" (Nossa tradução) 


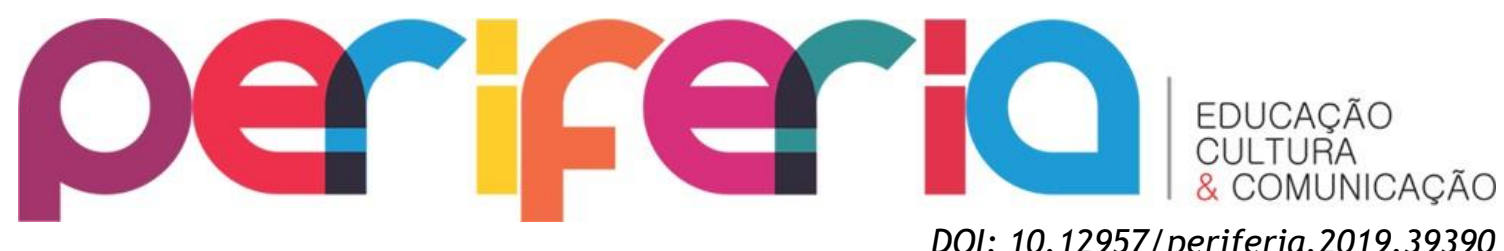

Wagner Moura por haver atuado em uma série televisiva como o falecido narcotraficante colombiano Pablo Escobar. Eleição essa que serviu para criar um efeito de sentido de ironia corroborado pelo senso comum: na Colômbia, somente há drogas. Até o próprio Escobar sente-se, no meme, “ofendido” com tal afirmação. Aqui, texto e imagem, como anteriormente mencionado em Hemais (2015, p. 32): “o verbal e o visual se complementam”, propulsionam esses efeitos de sentido a quem lê. Interessante observar que para a produção deste meme, os alunos ativaram seus conhecimentos de mundo em relação ao território colombiano (drogas, Pablo Escobar), mas este é ampliado quando do relato da prática da pesquisa sobre o país e, posteriormente, descobrem as obras do artista Fernando Botero e suas relações com a estética corporal, assim como o "Museo del Oro", com peças auríferas pertencentes aos povos originários. ${ }^{10}$

Em suma, a utilização dos memes em sala de aula nos suscitou diferentes saberes experienciais (TARDIF, 2002). O primeiro foi que percebemos que os alunos sabem muito mais sobre gêneros digitais do que nós, professores, imaginamos. O segundo foi reforçar que o celular é um artefato tecnológico profícuo à aprendizagem e negá-lo significa desperdiçar suas potencialidades pedagógicas. Outro ponto confirmar que produzir memes é uma atividade desejada pelos alunos. E, finalmente, constatou-se que urge-se cada vez mais trabalhar o componente cultural em sala de aula.

\section{Considerações Finais}

Neste trabalho, buscamos alinhar o conceito de multiletramentos a uma formação de professores para a justiça social, por meio de conceituações e relatos de experiências de professores e alunos. Objetivamos assim incentivar colegas docentes a refletirem sobre suas práticas docentes. Consideramos que a formação continuada pode auxiliar na desmitificação de mitos e aprofundar saberes para uma prática docente cada vez mais consciente, dinâmica, dialógica e multiletrada.

10 Para saber mais sobre Fernando Botero e o "Museo del Oro", visite: https://www.ebiografia.com/fernando_botero/ http://www.banrepcultural.org/bogota/museo-del-oro . Acesso em 13 de janeiro de 2019. 


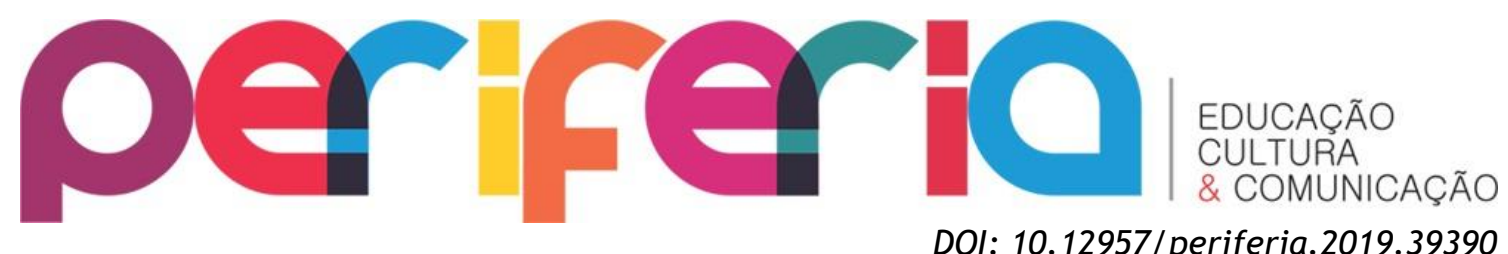

No entanto, o que propomos neste percurso é salientar a importância em ouvir tanto o docente quanto o discente, na busca por construir um currículo diversificado e baseado em suas singularidades.

Em síntese, a pedagogia dos multiletramentos é profícua ao trabalho com vistas à prática da justiça social, por ir além do refletir, tanto com os alunos em salas de aula de LA, quanto a importância da troca com docentes, em diversos espaços e adotando diferentes modelos da formação continuada. Desta forma, o processo da formação de professores pode se tornar ainda mais alinhado às problemáticas da sociedade. Como os multiletramentos propõem a interseção entre a multiplicidade cultural e a semiótica de textos circulantes no meio social, urge-se formar professores que compreendam que o ensino de línguas adicionais para fins específicos, ou seja, que busque considerar as singularidades dos alunos, precisa estar à serviço da cidadania e que possibilite a docência de modo interativo e dialógico.

\section{REFERÊNCIAS}

BORTONI-RICARDO, S.M. O professor pesquisador: introdução à pesquisa qualitativa. São Paulo: Parábola, 2008.

CARDOSO, J. S. Associações de professores e atuais políticas linguísticas para o ensino de línguas adicionais: estratégias e desafios. In GULLO, A.; BALGA, L. C.. Políticas linguísticas e ensino de LE no Brasil. Rio de Janeiro: UFRJ. http: / /seleufrj.wixsite.com/sele-ufrj/copia-livro-digital-i-sele . <Acesso em 31.01.19>

CELANI, M. A. (Org.) Professores Formadores em mudança: relato de um professo de reflexão e transformação da prática docente. Campinas: Mercado de Letras, 2010.

DINIZ-PEREIRA, J. E.; ZEICHNER, K. M. A pesquisa na formação e no trabalho docente. $2^{\mathrm{a}}$ ed. Belo Horizonte: Autêntica, 2011.

EAL - Ensino e Aprendizagem de Línguas: abordagens, metodologias $e$ tecnologias. Grupo de pesquisa da CNPq/UERJ. Site: www.eal.net.br. Endereço no diretor http://dgp.cnpq.br/dgp/espelhogrupo/3270478120833682. <Acesso em 31.01.19>

FREIRE, P. Pedagogia da Indignação, cartas pedagógicas e outros escritos. São Paulo: Editora UNESP, 2000. 


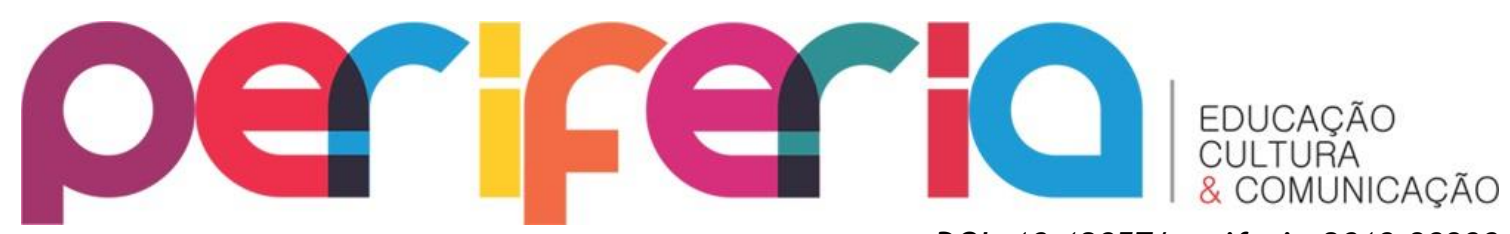

DOI: $10.12957 /$ periferia.2019.39390

GARCÍA CANCLINI, N. Culturas híbridas: estratégias para entrar e sair da modernidade. São Paulo. Edusp, 2008 [1989].

GRADDOL, D. English Next. Londres: British Council, 2006.

HEMAIS, B. J. W. Práticas pedagógicas no ensino de inglês: integrando gêneros discursivos e multimodalidade. In: HEMAIS, B. J. W. (Org.). Gêneros discursivos e multimodalidade: desafios, reflexões e propostas no ensino de inglês. Campinas, SP: Pontes, 2015.

JORGE, M. Línguas Estrangeiras em evidência: formação de professores, justiça social e letramentos. In: FERREIRA, M.; REICHMANN, C. Lynn; ROMERO, T. (orgs.) Construções identitárias de professores de línguas. Campinas: Pontes, 2016, p.121-136.

KALANTZIS, M.; COPE, B. Multiliteracies: the beginnings of an idea. In: COPE, B.; KALANTZIS, M. (Eds.). Multiliteracies: Literacy learning and the design of social futures. London: Routledge, 2000.

KATO, M. No mundo da escrita: uma perspectiva psicolinguística. São Paulo: Ática, 1986.

KLEIMAN, A. Os significados do Letramento: uma nova perspectiva sobre a p'ratica social da escrita. São Paulo: Mercado de Letras, 1995.

KRESS, G; VAN LEEUWEN, T. Multimodal Discourse: The modes and media of contemporary communication. Londres: Arnold, 2001.

LEFFA, J.V. (org.) O professor de línguas estrangeiras: construindo a profissão. $2^{\mathrm{a}}$ ed.Pelotas: Educat, 2008.

LEMOS, A. Cibercultura: tecnologia e vida social na cultura contemporânea. $6^{\text {a }}$ ed. Porto Alegre: Sulina, 2013 [2002].

LIBERALI, F. Formação crítica de educadores: questões fundamentais. $3^{\mathrm{a}}$ ed. Campinas: Pontes, 2015.

LIMA, G.; CASTRO, L. Meme digital: artefato da (ciber)cultura. Con(textos) Linguísticos, v.10, n.16, p. p.38-51, 2016.

MATEUS, E. OLIVEIRA, N. (orgs.). Estudos críticos da linguagem e formação de professores/as de línguas. Campinas: Pontes, 2014.

NOVOA, A. (ed.). Os professores e a sua formação. Tradução: Graça Cunha et al. Lisboa: Dom Quixote, 1992. 


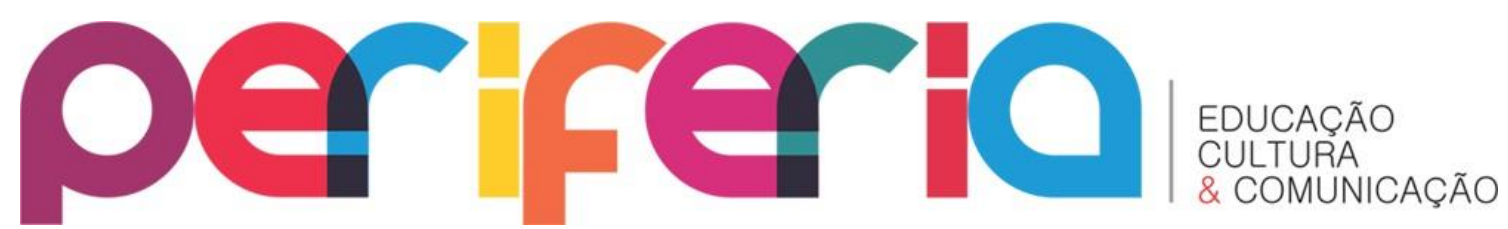

DOI: $10.12957 /$ periferia.2019.39390

PIMENTA, S.; FRANCO, M. A. S. Pesquisa em educação: possibilidades investigativas/formativas da pesquisa-ação. $2^{a}$ ed. São Paulo: Ed. Loyola, 2014.

RAJAGOPALAN, K. Por uma linguística crítica: linguagem, identidade e a questão ética. São Paulo: Parábola, 2003.

ROCHA, C. H.; BRAGA, D. B.; CALDAS, R. R. (Orgs.). Políticas linguísticas, Ensino de línguas e formação docente: desafios em tempos de globalização e internacionalização. Campinas: Pontes, 2015.

ROCHA, C. H.; MACIEL, R. F. (Orgs. ). Língua estrangeira e formação cidadã: por discursos e práticas. Campinas: Pontes, 2013.

RODGERS, C. Defining reflection: another look at John Dewey and reflective thinking. Teachers College. Record, v. 104, n. 4, p. 842-866, 2002.

ROJO, R. Letramentos múltiplos, escola e inclusão digital. São Paulo:

Parábola, 2009.

ROJO, R.; MOURA, Eduardo (orgs.) Multiletramentos na escola. São Paulo: Parábola, 2012.

ROJO, R. (org.) Escola conectada: os multiletramentos e as TICs. São Paulo: Parábola, 2013.

SANTAELLA, Lucia, Comunicação Ubíqua - Repercurssões na cultura e na educação. São Paulo: Editora Paulus, 2013.

SCHLATTER, M. GARCEZ, P. Línguas adicionais na escola: aprendizagens colaborativas em inglês. Erechim: Edelbra, 2012.

SILVA, M. Sala de aula interativa. $3^{\text {a}}$ edição. Rio de Janeiro: Quartet, 2002.

SILVA, S. Da técnica à crítica: contribuições dos novos letramentos para a formação de professores de língua inglesa. São Paulo: 2011, 243f. Tese. Instituto de Estudos da Linguagem. Universidade de São Paulo, São Paulo, 2011.

SCHON, D. A. Formar professores como profissionais reflexivos. In NOVOA (ed.). Os professores e a sua formação. Lisboa: Dom Quixote, 1992.

SOARES, M. Letramento: um tema em três gêneros. $7^{\text {a }}$ ed. São Paulo: Autêntica, 2017.

TARDIF, M. Saberes docentes e formação profissional. $4^{\mathrm{a}}$ ed. Rio de Janeiro: Vozes, 2002. 


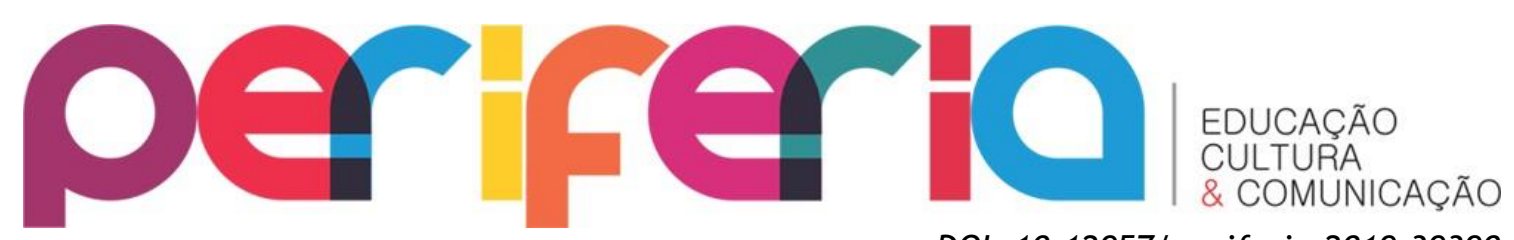

DOI: $10.12957 /$ periferia.2019.39390

TFOUNI, L. Adultos não alfabetizados: o avesso do avesso. São Paulo: Pontes, 1988.

THIOLLENT, M. Metodologia da pesquisa-ação. 18 ed. São Paulo: Cortez, 2011.

THIOLLENT, M. A inserção da pesquisa-ação no contexto da extensão universitária. In BRANDÃO, C. R.; STRECK, D. R. Pesquisa participante: o saber da partilha / a partilha do saber. Aparecida: Ed. Ideias e Letras, 2006a. (p. 151165)

THIOLLENT, M. (Org.). Pesquisa-ação e projeto cooperativo na perspectiva de Henri Desroche. São Carlos: EduFSCar, 2006b. 